\title{
BMJ
}

\section{Supplementation with antioxidants and folinic acid for children with Down's syndrome: randomised controlled trial}

\author{
Jill M Ellis, training fellow in evidence-based community child health, ${ }^{1}$ Hooi Kuan Tan, data manager, \\ Ruth E Gilbert, professor of clinical epidemiology, ${ }^{1}$ David P R Muller, professor of biochemistry, ${ }^{2}$ \\ William Henley, senior lecturer in statistics, ${ }^{3}$ Robert Moy, senior lecturer in community child health, ${ }^{4}$ \\ Rachel Pumphrey, research assistant, ${ }^{4}$ Cornelius Ani, specialist registrar and honorary lecturer, ${ }^{5}$ \\ Sarah Davies, research assistant, ${ }^{1}$ Vanessa Edwards, research fellow, ${ }^{6}$ Heather Green, research assistant, ${ }^{2}$ \\ Alison Salt, consultant developmental paediatrician, ${ }^{1}$ Stuart Logan, professor of paediatric epidemiology ${ }^{6}$
}

${ }^{1}$ Centre for Evidence-based Child Health, Centre for Paediatric Epidemiology and Biostatistics, UCL Institute of Child Health, London WC1N 1EH

${ }^{2}$ Biochemistry Unit, UCL Institute of Child Health

${ }^{3}$ School of Mathematics and Statistics University of Plymouth, Plymouth PL4 8AA

${ }^{4}$ Institute of Child Health, University of Birmingham, Birmingham B4 6NH

${ }^{5}$ Academic Unit of Child and Adolescent Psychiatry, Imperial College, St Mary's Campus, London W2 1PG

${ }^{6}$ Peninsula Medical School, St Luke's Campus, Exeter EX1 2LU Correspondence to: S Logan stuart.logan@pms.ac.uk

doi:10.1136/bmj.39465.544028.AE

\section{ABSTRACT}

Objectives To assess whether supplementation with antioxidants, folinic acid, or both improves the psychomotor and language development of children with Down's syndrome.

Design Randomised controlled trial with two by two factorial design.

Setting Children living in the Midlands, Greater London, and the south west of England.

Participants 156 infants aged under 7 months with trisomy 21.

Intervention Daily oral supplementation with antioxidants (selenium $10 \mu \mathrm{g}$, zinc $5 \mathrm{mg}$, vitamin A $0.9 \mathrm{mg}$, vitamin $\mathrm{E}$ $100 \mathrm{mg}$, and vitamin $(50 \mathrm{mg})$, folinic acid $(0.1 \mathrm{mg})$, antioxidants and folinic acid combined, or placebo.

Main outcome measures Griffiths developmental quotient and an adapted MacArthur communicative development inventory 18 months after starting supplementation; biochemical markers in blood and urine at age 12 months. Results Children randomised to antioxidant supplements attained similar developmental outcomes to those without antioxidants (mean Griffiths developmental quotient $57.3 \vee 56.1$; adjusted mean difference 1.2 points, $95 \%$ confidence interval -2.2 to 4.6 ). Comparison of children randomised to folinic acid supplements or no folinic acid also showed no significant differences in Griffiths developmental quotient (mean 57.6 v 55.9; adjusted mean difference $1.7,-1.7$ to 5.1 ). No between group differences were seen in the mean numbers of words said or signed: for antioxidants versus none the ratio of means was 0.85 (95\% confidence interval 0.6 to 1.2), and for folinic acid versus none it was 1.24 (0.87 to 1.77). No significant differences were found between any of the groups in the biochemical outcomes measured. Adjustment for potential confounders did not appreciably change the results.

Conclusions This study provides no evidence to support the use of antioxidant or folinic acid supplements in children with Down's syndrome.

Trial registration Clinical trials NCT00378456.

\section{INTRODUCTION}

Trisomy 21 (Down's syndrome) is the most common genetic cause of learning disability in the United Kingdom, with a birth prevalence of 1 per 1000 live births. ${ }^{1}$ Adults with Down's syndrome seem to age prematurely; many show Alzheimer's-like changes in their brains in their $30 \mathrm{~s}$ and $40 \mathrm{~s}^{2}{ }^{2}$ Neuronal changes are evident in infants with Down's syndrome. Postmortem studies have reported neuronal depletion and structural abnormalities of the brain during late gestation and early postnatal life. ${ }^{3}$ Why these changes occur is not fully understood, but involvement of the increased activity of two enzymes, copper/zinc superoxide dismutase and cystathionine $\beta$-synthase, both coded for on chromosome 21 , has been suggested.

Increased activity of superoxide dismutase in children with Down's syndrome is thought to cause oxidative damage to neuronal cells by increasing concentrations of hydrogen peroxide. ${ }^{4}$ Evidence that oxidative stress may be involved in the premature neuronal degeneration comes from several sources. Firstly, the cerebral cortex from fetuses with Down's syndrome was found to have increased activity of superoxide dismutase without a compensatory increase in glutathione peroxidase activity. ${ }^{5}$ Secondly, cortical neurones from fetuses with Down's syndrome have an increased concentration of intracellular oxygen derived free radicals and increased lipid peroxidation compared with controls. ${ }^{6}$ Thirdly, in vitro, fetal neurones in Down's syndrome have increased apoptotic degeneration, which seems to be prevented by the addition of antioxidants. ${ }^{6}$ Finally, studies have reported increased products of lipid peroxidation in the blood and urine of people with Down's syndrome compared with controls..$^{7-10}$

Evidence for a functional folate deficiency in Down's syndrome is based on analytical studies in plasma and in vitro studies. The enzyme cystathionine $\beta$-synthase catalyses the condensation of homocysteine with serine to form cystathionine. Increased concentrations of this enzyme in Down's syndrome leads to significantly 
reduced plasma concentrations of homocysteine, methionine, S-adenosylhomocysteine, and S-adenosylmethionine and thereby to a "folate trap" and a functional folate deficiency. ${ }^{11}$ In vitro studies have shown that adding selected nutrients (methionine, folinic acid, methyl B-12, thymidine, and dimethylglycine) to a cultured lymphoblastoid cell line with trisomy 21 causes a shift in one-carbon metabolism to a more normal profile. ${ }^{11}$

Clinical evidence that supplementation with folate, antioxidants, or both might ameliorate the effects of Down's syndrome has been evaluated in a systematic review. ${ }^{12-14}$ Four controlled trials of various doses and combinations of antioxidant vitamin and mineral supplementation given for three to eight months were identified in children and young people with Down's syndrome. ${ }^{15-19}$ The trials included a total of 150 participants aged between 6 months and 17 years. Younger children are thought to be more likely to benefit from nutritional interventions, but only one study, a crossover trial with 19 participants, included children under 5 years of age. ${ }^{16}$ All the trials have significant methodological weaknesses, and no metaanalysis was considered feasible both because of the heterogeneity of populations and outcomes and because of a lack of key data in the published papers. None of the trials reported any significant effect of antioxidants on cognitive function. Despite these findings, use of vitamin and mineral supplements is widespread in children with Down's syndrome in Europe and the United States as a result of the marketing of commercial preparations that claim

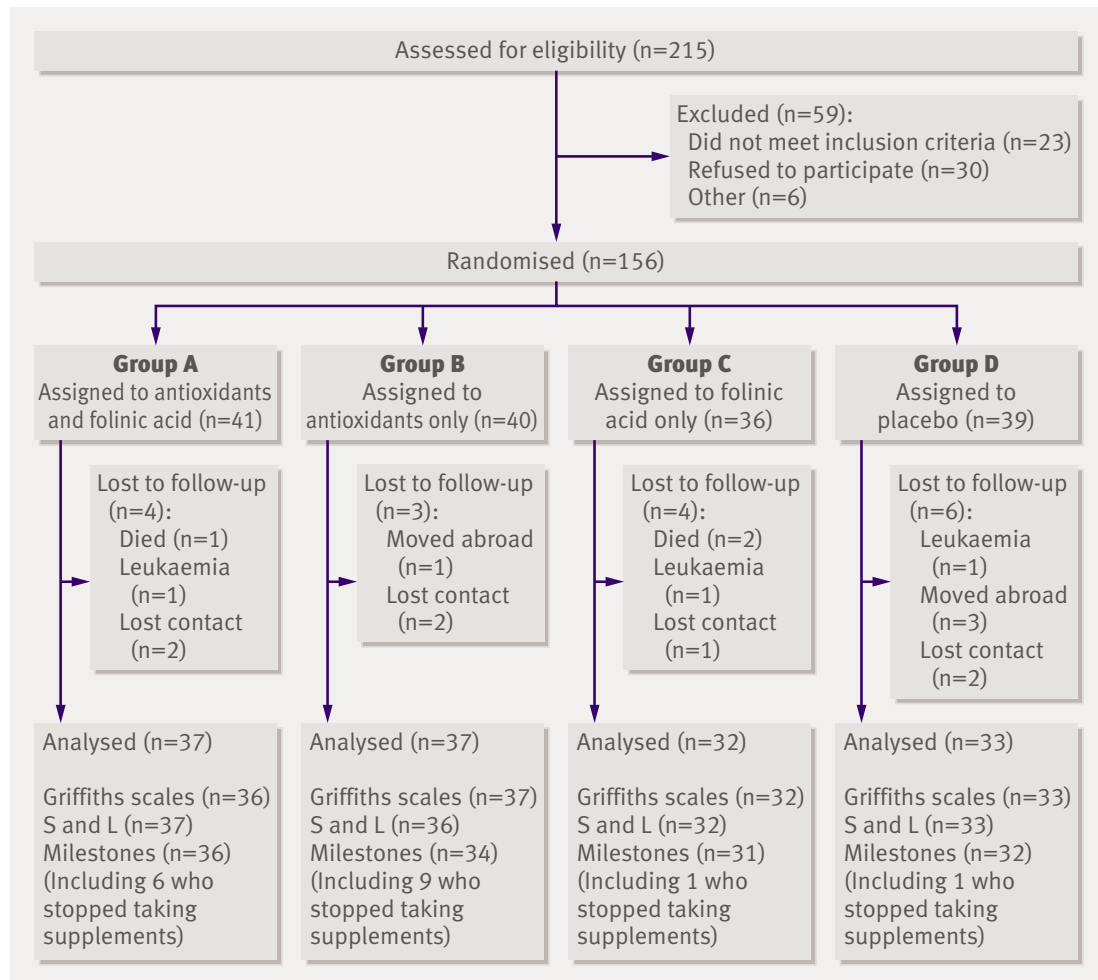

Trial profile. $\mathrm{S}$ and $\mathrm{L}=$ speech and language substantial benefits for children with Down's syndrome. We aimed to determine the benefits of supplementation with antioxidants or folinic acid for psychomotor development and the effect on certain biochemical markers of oxidative stress.

\section{METHODS}

Between May 2002 and February 2004 in Greater London and the West Midlands and, from January 2003, in Nottingham and the south west of England, we enrolled infants aged under 7 months with Down's syndrome. We excluded children with chromosome mosaicism or translocation, severe cardiac defects, or other serious long term illness and those from nonEnglish speaking families. We publicised the study through clinicians and parents' groups, and we visited interested families at home. Parents or legal guardians gave written informed consent. We used a four arm factorial design to randomise infants to receive a daily oral dose of antioxidants (selenium $10 \mu \mathrm{g}$, zinc $5 \mathrm{mg}$, vitamin A $0.9 \mathrm{mg}$, vitamin E $100 \mathrm{mg}$, and vitamin C $50 \mathrm{mg}$ ), folinic acid $(0.1 \mathrm{mg})$, a combination of the same doses of antioxidants and folinic acid, or a placebo (mannitol, malodextrin, and a natural food colour). All combinations were powders that appeared identical and could be mixed with food or drink. Pharmacists, who retained the allocation lists, allocated participants according to a random sequence generated by a Minim computer programme with minimisation for sex and presence of congenital heart disease. Supplements were prepared and packaged as identical sachets by Quintiles (Edinburgh), stored in the pharmacy, and mailed directly to the parents. We showed parents how to mix and administer the supplements at the enrolment visit, and the dosage was increased by $30 \%$ after the child's first birthday. Researchers were not aware of treatment allocation until the analyses were complete. Parents were blind to allocation until after the final outcome assessment but could thereafter request information directly from the pharmacy.

To detect a clinically important difference of 6 points on the Griffiths mental developmental quotient (equivalent to 0.5 of a standard deviation) with $85 \%$ power we needed 68 patients in each combined treatment group (antioxidants $v$ no antioxidants and folinic acid $v$ no folinic acid). We planned to recruit 200 infants, allowing for a 33\% loss to follow-up.

We monitored compliance with supplements in two ways. Firstly, at each visit or telephone call, we asked parents how many doses had been missed in the previous nine months. Secondly, we collected blood samples at approximately 1 year of age to measure plasma vitamin E concentrations. We collected venous samples into lithium heparin tubes, separated within three to four hours of collection and stored at $-80^{\circ} \mathrm{C}$ before analysis. We measured plasma vitamin $\mathrm{E}$ ( $\alpha$-tocopherol) with high performance liquid chromatography with fluorimetric detection by a modification of the method of Buttriss and Diplock. ${ }^{2021}$ We expressed vitamin $\mathrm{E}$ concentrations per millimole of plasma cholesterol, measured enzymatically on a COBAS 
Fara analyser with a kit supplied by ABX Diagnostics (Montpelier, France).$^{22}$

\section{Developmental outcomes}

One of four trained assessors measured the primary outcome, age adjusted general quotient on the Griffiths mental developmental scales (birth to 2 years, 1996 revised version), 18 months after enrolment. The Griffiths scales combine observations on how the child interacts with test equipment, together with developmental questions to parents. The number of "successes" the child achieves is converted to a developmental age equivalent. Scores are also produced on five subsections (locomotor, personal-social, hearing and language, coordination, and performance), and age adjusted subquotients are calculated.

Parents used a diary to prospectively record the date their child achieved major motor milestones such as sitting without support and walking. Missing records were completed on the basis of parental recall at visits nine and 18 months after enrolment. We used Cox regression to estimate treatment differences in recorded age of attainment of milestones.
We assessed language development with a modified version of the MacArthur communicative development inventory, a five section postal questionnaire. ${ }^{23}$ As this was designed for the United States, we replaced the standard word list (section B) with one used for UK children $^{24}$; we administered it to the parents at the 18 month home visit. We scored signed as well as spoken words and calculated the total number of gestures; phrases understood; and words said, signed and said, or signed. We adjusted the results for age.

\section{Biochemical outcomes}

We determined whether supplementation had any detectable effect on the antioxidant enzymes copper/ zinc superoxide dismutase and glutathione peroxidase in red blood cells. We measured superoxide dismutase with the RANSOD kit, which is based on the original method of McCord and Fridovich. ${ }^{25}$ We measured glutathione peroxidise with the RANSEL kit, which is based on the method of Paglia and Valentine. ${ }^{26}$ We ran both assays on a COBAS Fara analyser, and Randox Laboratories (County Antrim) supplied the RANSOD and RANSEL kits. We expressed both superoxide dismutase and

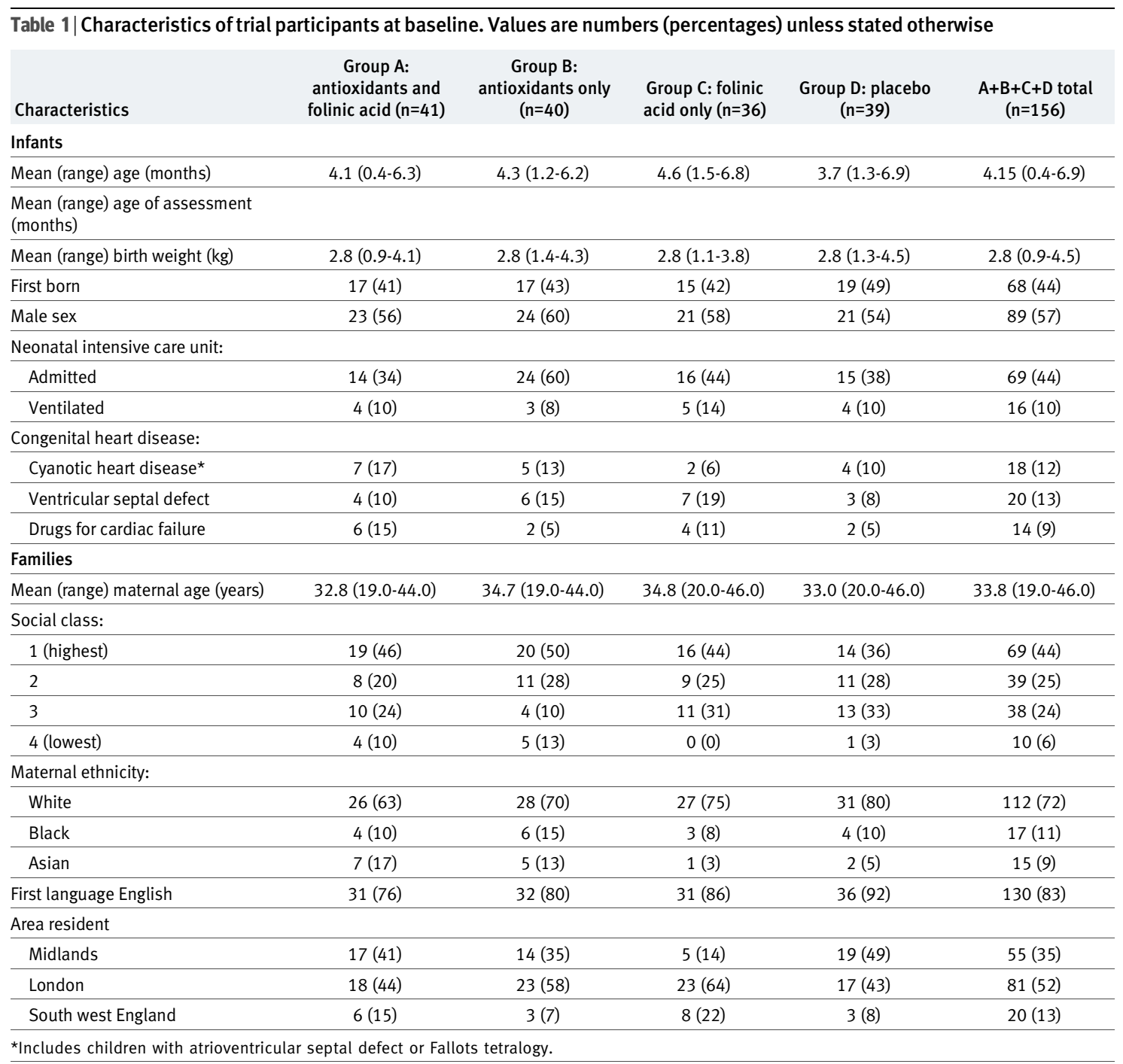


glutathione peroxidase activities per milligram of haemoglobin measured as cyanmethaemoglobin.

We measured urinary isoprostane concentrations as a marker of lipid peroxidation. We extracted the isoprostanes with a specific affinity sorbent supplied by Cayman Chemicals Company (Ann Arbor, USA) and estimated concentrations with gas chromatography-mass spectrometry by a modification of the method of Bessard et al, ${ }^{27}$ using the deuterated compound as an internal standard. The mass spectrometer was operated in the selected ion monitoring mode with ions at $\mathrm{m} / \mathrm{z} 481$ and 485 (deuterated compound used for quantification). We expressed concentrations of isoprostane per millimole of urinary creatinine, which was measured with a COBAS Fara analyser and a kit supplied by ABX Diagnostics (Montpelier, France), based on the Jaffe reaction. ${ }^{28}$

\section{Analyses}

We based all analyses on the intention to treat principle. In the primary analyses, we compared children who received antioxidants with those who did not and those who received folinic acid with those who did not. For continuous variables, we used regression analyses to estimate the differences between groups for each intervention and their confidence intervals, adjusted for the effect of the other intervention, area of residence, and baseline stratification variables. ${ }^{29}$ For dichotomous variables, we used logistic regression analyses to produce similarly adjusted estimates of the odds ratios and confidence limits. Where these measures were not age standardised, we adjusted for age at assessment. We logtransformed the number of words said, signed, or said or signed to ensure approximate normality of the residuals. We then expressed effect sizes as ratios of means adjusted for the effect of the other intervention, area of residence, and the baseline stratification variables. ${ }^{29}$ In secondary analyses, we further adjusted for variation in age, maternal ethnicity, social class, and neonatal problems. We also tested for an interaction between the interventions.

\section{RESULTS}

Enrolment, follow-up, and compliance

In all, 215 families were referred to the research team, of whom 59 either did not meet the inclusion criteria or

Table 2 | Unadjusted means` of Griffiths developmental quotient for all combinations of groups in factorial design

\begin{tabular}{|c|c|c|c|}
\hline \multirow[b]{2}{*}{ Antioxidants } & \multicolumn{2}{|c|}{ Folinic acid } & \multirow[b]{2}{*}{ Total } \\
\hline & Yes & No & \\
\hline Yes: & (Group A; $n=36$ ) & (Group B; n=37) & (Group A+B; n=73) \\
\hline Mean GQ & $58.7(9.3)$ & $57.4(9.8)$ & $58.0(1.1)$ \\
\hline No: & (Group C; n=32) & (Group D; $n=33$ ) & (Group C+D; $n=65)$ \\
\hline Mean GQ & $57.8(11.9)$ & $56.1(9.8)$ & $56.9(1.3)$ \\
\hline Total: & (Group $A+C ; n=68)$ & (Group B+D; n=70) & (Group $A+B+C+D ; n=138)$ \\
\hline Mean GQ & $58.3(1.3)$ & $56.8(1.2)$ & $57.5(0.9)$ \\
\hline
\end{tabular}

$\mathrm{GQ}=$ general quotient; group $\mathrm{A}=$ antioxidants and folinic acid; group $\mathrm{B}=$ antioxidants only; group $\mathrm{C}=$ folinic acid only; group $\mathrm{D}=$ placebo.

*Standard deviations in parentheses for individual group entries; standard errors shown for entries for totals. declined to participate; 156 infants (mean corrected age 4.2 months) were randomly assigned to one of four groups (figure). We abandoned the planned sample size of 200 infants because of slow recruitment and funding restrictions. Baseline characteristics were similar in the four groups, although a larger proportion of children in group B than in other groups had been admitted to a neonatal intensive care unit (the proportion needing ventilation was similar, however) and group Cincluded a smaller proportion of children from the Midlands and more from the south west (table 1)

Of the $17(11 \%)$ children lost to follow-up, three died, three developed leukaemia, and four moved abroad. The mean age at completion of the trial was 22 . 9 months (range 18.6-35.9 months). We assessed 139 children for the primary outcome of Griffiths developmental quotient after 18 months. The figure shows follow-up for other outcomes.

More of the children taking antioxidants than taking folinic acid alone or placebo stopped taking supplements $(15 / 74,20 \%$ v $2 / 65,3 \%$; relative risk $6.5,95 \%$ confidence interval 1.5 to 27$)$. Only children taking antioxidants stopped supplements because of vomiting or distress $(10 / 74 v 0 / 65 ; \mathrm{P}=0.002)$. No other notable adverse events were reported. For the children who continued on supplements, reported compliance was good; 78\% (94/122) of parents reported missing fewer than $10 \%(<54 / 547$ days $)$ of daily doses, and only $6 /$ $122(4 \%)$ missed more than $20 \%$ of doses $>104 /$ 547 days). We measured mean plasma vitamin E per millimole of cholesterol in 95 children, and this was almost twice as high in those taking antioxidants as in those taking placebo or folinic acid alone (10.76 v 5.92 $\mu \mathrm{mol} / \mathrm{mmol}$ cholesterol; $\mathrm{P}<0.0001)$.

At the end of the trial, we asked parents to guess which of the four supplements their child had been taking during the trial. Only 44/138 (32\%) parents felt able to guess, and of these only 11/44 (25\%) guessed correctly, which is consistent with chance.

\section{Effects on development}

We found no evidence for clinically or statistically significant effects of antioxidants or folinic acid on any of the outcomes measured. Table 2 shows the unadjusted mean Griffiths developmental quotients by group. Table 3 shows results for clinical and biochemical outcomes, adjusted for variables used to stratify randomisation. We found no significant differences between groups randomised and not randomised to antioxidants or between those randomised and not randomised to folinic acid on Griffiths developmental quotient or measures of language (table 3).

Supplementation also had no effect on the recorded age at attainment of motor milestones. Comparing infants allocated to antioxidants with those who were not, the hazard ratio for age of sitting without support was $1.10(95 \%$ confidence interval 0.77 to 1.56$)$ and that for standing was 1.25 (0.88 to 1.78 ). The results for children on folinic acid compared with those not on folinic acid were 1.25 ( 0.88 to 1.78$)$ for sitting and 1.14 (0.76 to 1.71$)$ for standing. None of these results changed appreciably 
after adjustment for area of residence, maternal ethnicity, birth weight, and social class.

\section{Enzyme activities and oxidative stress}

We obtained blood at 1 year of age from 107 children and measured enzyme activities on 99 samples. We obtained urine from 106 children and estimated isoprostane concentrations in 52 . We found no significant effect of antioxidant or folinic acid supplementation on superoxide dismutase or glutathione peroxidase activities or on the superoxide dismutase to glutathione peroxidase ratio or urinary isoprostane concentrations (table 3)

\section{DISCUSSION}

We found no evidence that either the antioxidants or the folinic acid supplements used in this trial had any effect on psychomotor development or language acquisition in children with Down's syndrome. Activities of the antioxidant enzymes (red cell superoxide dismutase, red cell glutathione peroxidase) and urinary isoprostane concentrations (a marker of lipid peroxidation) were similar in all groups, indicating that supplementation did not affect oxidative stress.

These findings are supported by a systematic review that included four randomised controlled trials of high dose vitamin supplements compared with placebo. ${ }^{14}$ Concerns that the design of previous studies could have biased in favour of no effect, owing to small sample size, short duration of supplementation (3-8 months), and late age of starting supplements, were considered in our study. Our sample size was sufficient to detect a clinically small effect in the main developmental outcome (6 Griffiths developmental quotient points), and loss to follow-up was only 11\%. Infants were started on supplements at a mean age of 4 months and

Table 3 | Developmental, speech, and biochemical outcomes for children randomised to antioxidants versus no antioxidants or to folinic acid versus no folinic acid. Values are mean (SD) unless stated otherwise

\begin{tabular}{|c|c|c|c|c|c|c|}
\hline \multirow[b]{2}{*}{ Outcomes } & \multicolumn{3}{|c|}{ Antioxidants $v$ no antioxidants } & \multicolumn{3}{|c|}{ Folinic acid $v$ no folinic acid } \\
\hline & Group A+B & Group $C+D$ & $\begin{array}{c}\text { Mean difference or ratio of } \\
\text { means }(95 \% \mathrm{Cl})\end{array}$ & Group $A+C$ & Group B+D & $\begin{array}{c}\text { Mean difference or ratio of } \\
\text { means }(95 \% \mathrm{Cl})\end{array}$ \\
\hline \multicolumn{7}{|l|}{ Griffiths mental developmental scales* } \\
\hline Number & 73 & 65 & - & 68 & 70 & - \\
\hline Total GQ & $58.1(9.5)$ & $56.9(10.8)$ & $1.2(-2.2$ to 4.6$)$ & $58.4(10.5)$ & $56.7(9.7)$ & $1.7(-1.7$ to 5.1$)$ \\
\hline \multicolumn{7}{|l|}{ Griffiths subscales*: } \\
\hline Locomotor & $54.1(12.0)$ & $51.1(12.5)$ & $3.0(-1.1$ to 7.0$)$ & $53.1(11.6)$ & $52.3(12.9)$ & $0.9(-3.2$ to 5.0$)$ \\
\hline Personal-social & $62.6(12.9)$ & $61.5(13.2)$ & $1.1(-3.2$ to 5.4$)$ & $62.7(12.5)$ & $61.5(13.5)$ & $1.2(-3.2$ to 5.6$)$ \\
\hline Hearing and language & $56.5(10.3)$ & $56.8(14.3)$ & $-0.3(-4.5$ to 3.9$)$ & $56.9(11.6)$ & $56.3(12.9)$ & $0.6(-3.6$ to 4.9$)$ \\
\hline Eye and hand & $61.9(11.6)$ & $60.9(12.3)$ & $1.0(-3.0$ to 5.1$)$ & $62.6(12.9)$ & $60.2(10.7)$ & $2.3(-1.8$ to 6.4$)$ \\
\hline Performance & $60.8(15.7)$ & $59.3(15.5)$ & $1.5(-3.8$ to 6.8$)$ & $61.8(16.5)$ & $58.5(14.6)$ & $3.3(-2.1$ to 8.6$)$ \\
\hline \multicolumn{7}{|l|}{ Receptive language $\dagger$} \\
\hline Number & 73 & 65 & - & 69 & 69 & - \\
\hline Total gesture score & $31.3(11.9)$ & $32.4(11.4)$ & $-1.1(-5.1$ to 2.9$)$ & $32.0(11.2)$ & $31.7(12.1)$ & $0.3(-3.8$ to 4.4$)$ \\
\hline Phrases understood & $15.7(6.6)$ & $16.5(7.4)$ & $-0.8(-3.2$ to 1.6$)$ & $16.3(6.8)$ & $15.8(7.2)$ & $0.5(-2.0$ to 2.9$)$ \\
\hline \multicolumn{7}{|l|}{ Expressive language } \\
\hline Number & 73 & 65 & - & 69 & 69 & - \\
\hline Mean No of words child says§ & $3.2(3.6)$ & $4.9(6.3)$ & $0.82(0.60$ to 1.12$)$ & $4.7(6.2)$ & $3.4(3.7)$ & $1.05(0.76$ to 1.45$)$ \\
\hline Mean No of words child signs§ & $6.0(7.8)$ & $6.1(7.6)$ & $0.93(0.66$ to 1.31$)$ & $7.2(8.5)$ & $4.9(6.5)$ & 1.33 (0.93 to 1.89$)$ \\
\hline $\begin{array}{l}\text { Mean No of words child says or } \\
\text { signs§ }\end{array}$ & $8.2(8.3)$ & $9.7(9.6)$ & $0.86(0.61$ to 1.21$)$ & $10.4(9.9)$ & $7.3(7.7)$ & 1.24 (0.87 to 1.77$)$ \\
\hline \multicolumn{7}{|l|}{ Blood analysisף } \\
\hline Number & 52 & 47 & - & 50 & 49 & - \\
\hline $\begin{array}{l}\text { Superoxide dismutase (SOD-1) (U/ } \\
\mathrm{mg} \mathrm{Hb})\end{array}$ & $4.0(1.1)$ & $3.8(1.1)$ & $0.2(-0.2$ to 0.6$)$ & $3.9(1.2)$ & $3.9(0.9)$ & $0.1(-0.4$ to 0.5$)$ \\
\hline $\begin{array}{l}\text { Glutathione peroxidise (GSH-Px) (U/ } \\
\mathrm{mg} \mathrm{Hb})^{\star \star}\end{array}$ & $66.3(34.8)$ & $65.3(37.7)$ & $4.2(-9.3$ to 17.7$)$ & $71.7(41.4)$ & $60.2(29.4)$ & $7.6(-6.0$ to 21.3$)$ \\
\hline Ratio of SOD-1 to GSH-Px§†† & $0.077(0.06)$ & $0.077(0.05)$ & $0.99(0.79$ to 1.24$)$ & $0.077(0.06)$ & $0.077(0.04)$ & 1.01 (0.81 to 1.27$)$ \\
\hline \multicolumn{7}{|l|}{ 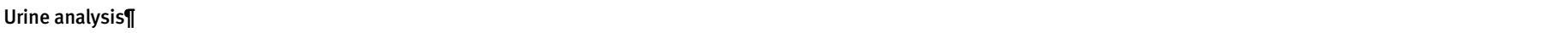 } \\
\hline Number & 26 & 26 & - & 23 & 29 & - \\
\hline $\begin{array}{l}\text { Isoprostanes§ (pmol/mmol } \\
\text { creatinine) }\end{array}$ & $2264(2202)$ & 2306 (2399) & 1.10 (0.61 to 2.00$)$ & $2243(2143)$ & 2318 (2419) & $0.92(0.52$ to 1.61$)$ \\
\hline \multicolumn{7}{|c|}{ 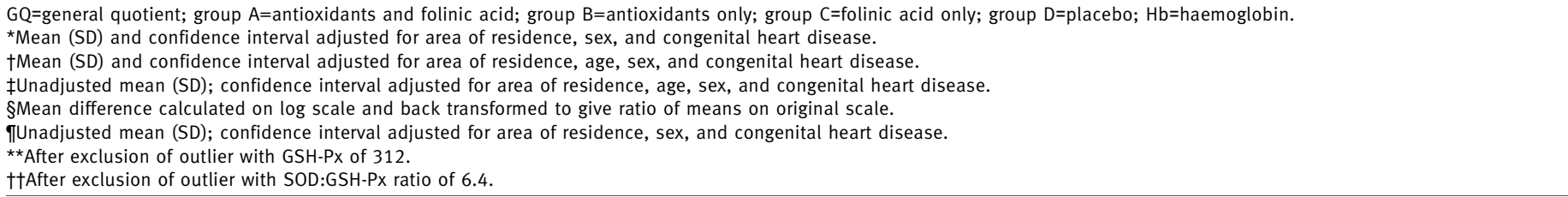 } \\
\hline
\end{tabular}

††After exclusion of outlier with SOD:GSH-Px ratio of 6.4 . 


\section{WHAT IS ALREADY KNOWN ON THIS TOPIC}

Developmental delay in children with Down's syndrome may result from neuronal damage due to increased oxidative stress, abnormal folate metabolism, or both

Cultured neuronal cells from fetuses with Down's syndrome undergo apoptotic death more rapidly than those from unaffected fetuses, but this is reversed by addition of antioxidants

No high quality in vivo evidence exists to show if giving antioxidants or folinic acid affects neurodevelopment in infants with Down's syndrome

\section{WHAT THIS STUDY ADDS}

Daily supplementation with antioxidants, folinic acid, or both did not alter psychomotor or language development in children with Down's syndrome

continued for 18 months. Reported compliance was good and confirmed by increased plasma vitamin $\mathrm{E}$ concentrations in those children on supplementation. Concealment of allocation was good, and blinding proved to be effective as only $8 \%$ of parents correctly guessed which supplement their child was taking.

One limitation of our study was the relatively low dose of supplements compared with commercially available preparations (Nutrivene-D and Euro TNI), ${ }^{30}$ which may have been inadequate to affect biochemical pathways. The doses used in the study were $100 \%$ of the recommended daily allowance for vitamin $\mathrm{E}$, zinc, and selenium and $200 \%$ of the recommended daily allowance for vitamin $\mathrm{C}$ and folinic acid. ${ }^{31}$ We were reluctant to use higher doses, as data on the safety of high doses for young children are lacking and high dose vitamin $\mathrm{C}$ may in fact exhibit pro-oxidant properties. ${ }^{32}$ Our results do not exclude the possibility that subtle effects of supplementation on development might be detectable given longer term supplementation and follow-up.

The mechanisms responsible for the neuronal changes in Down's syndrome are likely to be complex. Superoxide dismutase and cystathionine $\beta$-synthase are just two of many gene products coded for on chromosome 21. The variable phenotype of Down's syndrome could result from an interaction involving any of the genes or gene products coded on this chromosome. ${ }^{33}$ An aneuploid mouse strain carrying human chromosome 21 has recently been developed, and this might provide further insights into the complex mechanisms involved in Down's syndrome. $^{34}$

As Down's syndrome has a profound effect on the lives of children and their families, parents will probably have a low threshold for trying interventions. Commercially available nutritional supplements cost between $£ 15$ and $£ 30$ ( $€ 20-40$; \$30-60) a month, and, as they are food supplements, they do not have to be produced to the same high standards as prescription drugs. The only short term side effect we found was a significant increase in vomiting in infants taking antioxidants, but the side effects of higher dose preparations used over a long period are unknown. The widely held belief that vitamins are harmless has been challenged by a recent systematic review and meta-analysis of controlled trials, which suggested that antioxidant supplementation is associated with increased mortality across a range of conditions. ${ }^{3536}$

\section{Conclusion}

Our study provides no evidence to support the use of antioxidants or folinic acid in young children with Down's syndrome. Parents who choose to give supplements to their children need to weigh their hope of unproved benefits against potential adverse effects from high dose, prolonged supplementation.

We thank the families and children involved in the vitamins and minerals trial and the paediatricians who referred them to us. We also thank Joan Morris and Eva Alberman from the National Down Syndrome Cytogenetic Register, Linda Haynes at the Royal College of Paediatrics and Child Health Research Unit, and Carol Cummins at the clinical trials unit in Birmingham, who gave advice and helped with recruitment; James Law, who helped to adapt the MacArthur speech and language questionnaire, and Denise Challis, who provided training and support on the Griffiths mental developmental scales; the funding charities (Down's Syndrome Association, Fondation Jérôme Lejeune, Down Syndrome Research Foundation), who also helped to publicise the study to parents, and the Szeben Peto Foundation; Members of the Down Syndrome Medical Interest Group, particularly Jennifer Dennis, who gave advice on trial design and helped to publicise the study to other doctors. Other members of the V\&M trial team were T Cole, S Grantham-McGreggor, S Riggs, and M Rogers.

Contributors: CA, SGMcG, RM, and DPRM were applicants on the original grant to the Down's Syndrome Association and Fondation Jérôme Lejeune. TC gave statistical advice in the design phase. CA, SGMcG, SL, REG, and JME wrote the protocol and applied for multi-research ethics committee approval. HKT, JME, RP, and VE set up the database. JME was trial coordinator and, together with RM and SL, supervised research assistants SR, MR, SD, RP, and VE, who visited families and collected and imported data. AS gave advice on developmental assessment and other aspects of trial conduct. JME, SD, RP, and SL did the Griffiths assessments. $\mathrm{HG}$ and DPRM did the biochemical analyses. HKT supervised data cleaning by RP and VE and, with JME, SL, and REG, did the preliminary analysis with advice from AS. WH did the final adjusted analysis. JME, REG, DPRM, and SL drafted the paper, which was commented on by the other authors. SL is the guarantor.

Funding: The study was funded by the Down's Syndrome Association, Fondation Jérôme Lejeune, Down Syndrome Research Foundation, and Szeben Peto Foundation. The funding sources had no role in the study design; in the collection, analysis, and interpretation of data; in the writing of the report; or in the decision to submit the paper for publication. This work was done at GOSH/UCL Institute of Child Health, which received proportion of funding from the Department of Health's NIHR Biomedica Research Centres funding scheme.

Competing interests: None declared

Ethical approval: London Multi-Research Ethics Committee.

Provenance and peer review: Not commissioned; externally peer reviewed.

1 Huang T, Watt H, Wald N, Morris J, Mutton D, Alberman E, et al. Birth prevalence of Down's syndrome in England and Wales 1990 to $1997 . J$ Med Screen 1998;5:213-4.

2 Kolata G. Down syndrome-Alzheimer's linked. Science 1985;230:1152-3.

3 Becker L, Mito T, Takashima S, Onodera K. Growth and development of the brain in Down syndrome. Prog Clin Biol Res 1991;373:133-52.

4 Sinet PM. Metabolism of oxygen derivatives in Down's syndrome. Ann NYAcad Sci 1982;396:83-94.

5 Brooksbank BW, Balazs R. Superoxide dismutase, glutathione peroxidase and lipoperoxidation in Down's syndrome fetal brain. Brain Res 1984;318:37-44.

6 Busciglio J, Yankner BA. Apoptosis and increased generation of reactive oxygen species in Down's syndrome neurons in vitro. Nature 1995;378:776-9. 
7 Jovanovic SV, Clements D, MacLeod K. Biomarkers of oxidative stress are significantly elevated in Down syndrome. Free Radic Biol Med 1998;25:1044-8.

8 Kedziora J, Bartosz G, Gromadzinska J, Sklodowska M, Wesowicz W, Scianowski J. Lipid peroxides in blood plasma and enzymatic antioxidative defence of erythrocytes in Down's syndrome. Clin Chim Acta 1986;154:191-4.

9 Krishna Murthy DS, Murthy SK, Patel JK, Banker GN, Shah VC. Inherited pericentric inversion of Y-chromosome with trisomy 21: a case report. Ann Genet 1989;32:47-51.

10 Bras A, Monteiro C, Rueff J. Oxidative stress in trisomy 21: a possible role in cataractogenesis. Ophthalmic Paediatr Genet 1989;10:271-7.

11 Pogribna M, Melnyk S, Pogribny I, Chango A, Yi P, James S. Homocysteine metabolism in children with Down syndrome: in vitro modulation. Am J Hum Genet 2001;69:88-95.

12 Lejeune J. Pathogenesis of mental deficiency in trisomy 21. Am J Med Genet Suppl 1990;7:20-30.

13 Gelb MJ. Targeted nutritional intervention (TNI) for children with Down syndrome. Padiatriche Praxis 2001;59:703-8.

14 Salman M. Systematic review of the effect of therapeutic dietary supplements and drugs on cognitive function in subjects with Down syndrome. Eur J Paediatr Neurol 2002;6:213-9.

15 Bennett FC, McClelland S, Kriegsmann EA, Andrus LB, Sells CJ. Vitamin and mineral supplementation in Down's syndrome. Pediatrics 1983;72:707-13.

16 Bidder RT, Gray P, Newcombe RG, Evans BK, Hughes M. The effects of multivitamins and minerals on children with Down syndrome. Dev Med Child Neurol 1989;31:532-7.

17 Smith GF, Spiker D, Peterson CP, Cicchetti D, Justine P. Use of megadoses of vitamins with minerals in Down syndrome. J Pediatr 1984;105:228-34

18 Weathers C. Effects of nutritional supplementation on IQ and certain other variables associated with Down syndrome. Am J Ment Defic 1983;88:214-7.

19 Ani C, Grantham-McGregor S, Muller D. Nutritional supplementation in Down syndrome: theoretical considerations and current status. Dev Med Child Neurol 2000;42:207-13.

20 Metcalfe T, Bowen DM, Muller DP. Vitamin E concentrations in human brain of patients with Alzheimer's disease, fetuses with Down's syndrome, centenarians, and controls. Neurochem Res 1989;14:1209-12.

21 Buttriss JL, Diplock AT. High-performance liquid chromatography methods for vitamin E in tissues. Methods Enzymol 1984;105:131-8.

22 Allain CC, Poon LS, Chan CS, Richmond W, Fu PC. Enzymatic determination of total serum cholesterol. Clin Chem 1974;20:470-5.

23 Fenson L, Dale PS, Reznick JS, Thal D, Bates E, Hartung JP, et al. MacArthur communicative development inventory: users guide and technical manual . San Diego, CA: Singular Publishing Company, 1993.

24 Law J. The implications of different approaches to evaluating intervention: evidence from the study of language delay/disorder. Folia Phoniatr Logop 2004;56:199-219.

25 McCord JM, Fridovich I. The utility of superoxide dismutase in studying free radical reactions: I. Radicals generated by the interaction of sulfite, dimethyl sulfoxide, and oxygen. J Biol Chem 1969;244:6056-63.

26 Paglia DE, Valentine WN. Studies on the quantitative and qualitative characterization of erythrocyte glutathione peroxidase. / Lab Clin Med 1967;70:158-69.

27 Bessard J, Cracowski JL, Stanke-Labesque F, Bessard G. Determination of isoprostaglandin F2alpha type III in human urine by gas chromatography-electronic impact mass spectrometry: comparison with enzyme immunoassay. J Chromatogr B Biomed Sci Appl 2001;754:333-43.

28 Vasiliades J. Reaction of alkaline sodium picrate with creatinine: I. Kinetics and mechanism of formation of the mono-creatinine picric acid complex. Clin Chem 1976;22:1664-71.

29 Montgomery AA, Peters TJ, Little P. Design, analysis and presentation of factorial randomised controlled trials. BMC Med Res Methodol 2003;3:26.

30 Down's Syndrome Research Foundation. Targeted nutritional intervention ... (for Down's syndrome). 2007. www.dsrf.co.uk/ Alternate Therapies/TNI\%20Printout.htm.

31 Department of Health. Dietary reference values for healthy children: vitamins and minerals . London: HMSO, 1991.

32 Podmore ID, Griffiths HR, Herbert KE, Mistry N, Mistry P, Lunec J. Vitamin C exhibits pro-oxidant properties. Nature 1998;392:559.

33 Moore CS, Roper RJ. The power of comparative and developmental studies for mouse models of Down syndrome. Mamm Genome 2007;18:431-43.

34 O’Doherty A, Ruf S, Mulligan C, Hildreth V, Errington ML, Cooke S, et al. An aneuploid mouse strain carrying human chromosome 21 with Down syndrome phenotypes. Science 2005;309:2033-7.

35 Bjelakovic G, Nikolova D, Gluud LL, Simonetti RG, Gluud C. Mortality in randomized trials of antioxidant supplements for primary and secondary prevention: systematic review and meta-analysis. JAMA 2007;297:842-57.

36 Miller ER 3rd, Pastor-Barriuso R, Dalal D, Riemersma RA, Appel LJ, Guallar E. Meta-analysis: high-dosage vitamin E supplementation may increase all-cause mortality. Ann Intern Med 2005;142:37-46.

Accepted: 3 January 2008 